\title{
A Study on Transitions to Knowledge-Based Service in China's Publishing Industry
}

\author{
Li Zhang ${ }^{1} \cdot$ Suping $\mathrm{Wu}^{1} \cdot$ Dan Zhou ${ }^{1}$
}

Published online: 22 July 2020

(c) Springer Science+Business Media, LLC, part of Springer Nature 2020

\begin{abstract}
At present, the publishing industry in China has entered the stage of knowledgebased service in digital transformation. This article introduces the four stages of the digital transformation in the Chinese publishing industry with a focus on knowledge-centered service, including the origin and meaning of the concept, the service transformation of traditional Chinese publishing industry, and the knowledge management of Internet companies and new media companies. In China, knowledgebased service of the publishing industry usually refers to a brand-new service model that integrates content creation, production, dissemination, and even application. In response to the impact of the Internet and seize the development opportunities brought by big data and artificial intelligence, the Chinese publishing industry, from traditional publishing houses to Internet-based We-Media, is actively exploring various ways and models of knowledge-based service transformation. This article illustrates the current knowledge-based services of the publishing industry in China with the case study of some pilot projects and paying for knowledge online.
\end{abstract}

Keywords Publishing $\cdot$ Knowledge-based service $\cdot$ Digital publishing

Since the late twentieth century, the global publishing industry has been trying out digital transformation. The digital transformation of the publishing industry in China began in the 1990s, known as "non-network electronic publication". The feature of this type of publications is that publications have additional content forms, such as databases, learning courseware, integrated music products, electronic games, etc., or physical items such as floppy disks, CDs, CD-ROMs, DVD-ROMs, etc. The second stage of the digital transformation of China's publishing industry started around 2000, known as "Web Publishing." It is a new content publishing and distribution model that emerged with the rise of the Internet. The characteristics of We Publishing are that, on the one hand, traditional publishing companies have established their

Li Zhang

zhangli@bqpmo.com

$1 \quad$ R\&D Center, Chinese Academy of Press and Publications, Beijing, China 
own websites to disseminate their products through the Internet; on the other hand, some Internet companies have also established content distribution and sharing platforms to participate in the content production. The third stage of the digital transformation of China's publishing industry is marked by the first "China Digital Publishing Expo" held in China in 2005. This period of digital transformation is generally referred to as "digital publishing," when contents are rich and diverse, ranging from database products to reading terminals that combine various hardware and software; there are both e-commerce platforms and Internet content creation platforms. The most prominent feature of this period is the rise of various original literature created on the online platforms. In this regard, Internet companies have played a leading role, while traditional publishing companies have a relative passive response. The fourth stage of the digital transformation of China's publishing industry is AI-based knowledge management. In this era, the publishing industry relies on some more advanced technologies, such as big data, cloud computing, natural language processing, artificial intelligence, AR/VR, mobile terminals, etc., to fragment digital content and then mark and associate the fragmented content semi-automatically, so as to provide readers with targeted knowledge retrieval and knowledge services; vertical application of knowledge management has even begun to appear in certain fields. In China, sometimes the publication of this era is called "smart publishing" to reflect the AI-based service of publishing.

\section{The Origin and Related Studies of Knowledge-Based Service}

In China, we often come across the literally translated term "Knowledge Service", which, according to our preliminary inquiry, is rarely used by foreign scholars. Internationally, the application of knowledge is more emphasized in different service industries, including "Knowledge Industries", "Knowledge Economy", "Knowledge-focused management", " Knowledge-Centered Service " etc.

Based on the literature review, as early as 1963, the Austrian-American economist Fritz Machlup used the term "Knowledge industries" [1] to highlight that it an industry featuring intensive use of technology and human capital. Compared with other industries, the knowledge industry is based on knowledge and technology to generate value, including applications in the education industry, consulting industry, communications industry and medical and health care industry. In 1969, economist Peter F. Drucker coined the term "knowledge economy" [2], referring to the use of knowledge to create goods and services, and emphasizing the importance of knowledge and skills in the service economy. In the era of the knowledge economy, the value of intellectual property rights is particularly prominent.

The concept of Knowledge-focused Management was developed in the management consulting community in the mid-1970s. In 1975, as one the first organizations to adopt the practice of Knowledge-focused Management without the help of information technology, Chaparral Steel built its internal organizational structure and corporate strategy directly on a clear specific knowledge-based management to ensure its leading position in technology and market. 
The concept of Knowledge-Centered Service, proposed by the non-profit alliance of service and support organization "Consortium for Service Innovation," emerged in 1992 [3]. Knowledge-Centered Service refers to integrating the use of knowledge databases into the workflow. KCS, spelled out as "Knowledge-Centered Support" in early days, refers to the service delivery method that uses knowledge as the key asset of the organization, and its foundation is to capture, construct, and reuse knowledge with technological support.

Under general understanding, Knowledge Service is a concept developed from such theories as information management, knowledge management, and strategic learning/instruction. This concept was first studied and applied in the field of medicine in China; it was later adopted in corporate marketing, extended to the field of library science, and then widely studied in the field of informatics.

Through systematic literature review, we found that the Chinese research on "knowledge-based service" originated in the 1990s. In 1994, Dai Guangqiang published a paper titled "Expansion of medicine from technical services to knowledge services-a new era of medical development". In this paper, he mentioned that the knowledge service of medicine is to improve people's self-care capabilities through the spread of medical knowledge and skills. In 1995, Lu Xiujin and Wang Zenghua expressed a similar view in their article "The Implication of Medical Knowledge Service in Leprosy Rehabilitation".

Subsequently, "knowledge-based service" was studied and adopted in the field of corporate marketing. At this time, "knowledge-based service" is the process in which companies promote the product-related knowledge and information to consumers. It is the most important integral part of knowledge marketing [4]. Inspired by the "knowledge-based service" provided by enterprises to consumers, libraries and archives also began to encourage their staff to familiarize themselves with the respective collections and retrieval methods so as to help people know how to use knowledge to solve problems in their lives and work [5].

Ren Junwei's "Knowledge Economy and Library Knowledge-based Services" published in "Documentation, Information \& Knowledge" in 1999 is considered to be the first study in this field. The author believes that "knowledge-based services are the deepening services of documentation and literature." The library should "reform the service mechanism and provide a more comprehensive knowledge-oriented service." In 2000, Zhang Xiaolin proposed "to position the core capacity of library and information services in knowledge-based service" in his article "Towards Knowledge-based Service: Looking for Improvement of Library and Information Services in the New Century".

With the development of the Internet, Zhang Xiuzhen and Pei Fei introduced information technology, artificial intelligence research and other elements into the concept of "knowledge-based service" for the first time in their article "Knowledgebased Service in the Network Environment," published in 2002. In the same year, Sun Chengjiang and Wu Zhengjing first proposed in the article "Knowledge, Knowledge Management, and Web-based Knowledge Service" that experiential services should be included in knowledge-based services, such as user discussion groups, interactive online classrooms, and multimedia internships to provide programmatic and systematic knowledge services. In 2004, the concept of "knowledge network" 
was introduced. Researchers suggested that in order to maximize the benefits of China's web-based information resources, an online knowledge service system and information service system equipped with such technologies and tools as artificial intelligence, semantic analysis, data mining, and knowledge graphs, should be established as soon as possible [6]. But the AI technologies mentioned at this time were only concepts.

With the development of blogging, its knowledge services and community communication were gradually included in the theoretical research on the knowledgebased services. Through fully personalized blogs, the individual's desire for creativity was evoked, effectively forming a knowledge community [7].

With the advancement of big data and cloud computing technologies, as the key technology in knowledge service activities, database and knowledge discovery gradually become more prominent in their application. Big data knowledge service is a new information service model for solving multi-dimensional processing of structured, semi-structured and unstructured data. It is a new development of an embedded collaborative knowledge service model [8]. In the cloud computing environment, the professional knowledge service platform and professional knowledge service launched by libraries has become a research hot topic.

The development of artificial intelligence has brought changes to knowledgebased services. The first is the transformation of thinking of knowledge. It not only taps knowledge from the perspective of user needs, but also actively discovers related knowledge and predicts future needs of users. Second, it is the diversification of knowledge services, ranging from documentation, digital books and periodicals, but also new media forms such as search engines, know-how communities, and social networks; and finally, the intelligent knowledge-based services. The answer can be given directly through artificial intelligence, without the need for users to extract knowledge from many related entries [9].

Today, in the backdrop of media integration, academic journals and publishing companies are also actively exploring new models of knowledge-based services. Relevant researchers believe that academic journals should make full use of new media, big data and other technologies to create targeted knowledge-based services, such as intellectual celebrity IP, online video courses, online quizzes, information subscription push, popular topics, and online seminar live streaming [10]. Digital publishing should explore and carry out commodities-turn-services, communities building, long-tail resources and content value return, etc., to establish a mature knowledge-based service system [11].

\section{Traditional Publishing in Transition to Knowledge-Based Service}

The advent of the Internet has an unprecedented impact on the traditional publishing industry. This is an indisputable fact we have observed in the past 20 years. It is true both at home and abroad. However, the impact has mainly concentrated on the mass publishing market, manifested in the rise of e-commerce, original contents for online platforms, internet communities and We-Media. The academic publishing market is also under the impact of AI-based and knowledge-based services in recent 
years. We originally thought that the academic publishing industry is not vulnerable to the impact of new technologies due to its exclusive and rigid content, and its fixed and unique target audience. We might well sit back and relax and continue the traditional service model, but now it seems that this assessment may be too optimistic and conservative.

Inevitably, the academic publishing industry is also under the impact of new technologies even with unique advantages and a higher bar for entry. It may be the last area of traditional publishing hit by new technologies. In China, such an impact is mainly manifested in the online publication and dissemination of academic journals, including the emergence of OA platforms, customized and knowledge-based retrieval, such as CNKI. Another impact is the rise of the Internet knowledge community, such as Baidu Baike, Baidu Wenku, Zhihu and so on.

This article here is to highlight how traditional Chinese academic publishing houses responded to and explored the impact of artificial intelligence and knowledge-based services. We name the service model of the online knowledge community as UGC (User Generated Content), and that of the traditional publishing as PGC (Professional Generated Content), which is to provide readers with filtered, reviewed, and edited professional knowledge. Thanks to a series of publishing processes, the knowledge content provided by traditional professional publishing houses is generally accurate. At the same time, Chinese academic publishing houses are actively exploring the hybrid model of UGC + PGC.

In 2015, the Chinese Academy of Press and Publication where the author worked officially launched the pilot work of knowledge resource services. From 2015 to 2018, the Academy organized the selection and evaluation of three batches of pilot units to implement the knowledge resource service model, with a total of 110 participating publishing houses, universities and research institutes, and Internet companies. Under the guidance of the former General Administration and the current Publicity Department of the Communist Party of China, the Academy has completed the compilation of a knowledge resource service standard system and the building of a knowledge service platform (portal website and official account). Under the overall planning, each professional publishing house has independently established the respective knowledge service platform and began to provide services.

We have established a portal website as the Knowledge Resource Service Center. The main contents provided include: professional knowledge retrieval, research paper retrieval, bibliographic information query, publishing and knowledge service standard query, academic publication evaluation aggregation, etc., and open access to OA journals, digital copyright protection, block chain certification, digital content publicity inquiry and other services. The portal website and the academic knowledge service platform of each publishing unit adopt a distributed deployment model, that is, each publishing unit builds its own network and operates independently, and through the portal website to realize the interconnection of search diversion and user sharing.

At present, the knowledge resource service center portal has access to 19 knowledge service systems of 18 publishing houses, has collected more than 5.1 million publication metadata entries, more than 3 million journal papers, and has trained 30 million entries for fundamental knowledge map, more than 2 million knowledge 
entities, and more than 11 million entity relationship data. The pilot units are also actively promoting the transformation and upgrading of knowledge-based services. Each unit has developed more than 100 knowledge-based service products.

In general, the pilot units are currently in a good position in terms of research, development, operation, and promotion of knowledge-based service products. Basically, each of them has at least one knowledge-based service platform or product that has been put into operation. Some publishing agencies have achieved better revenue. But there are also some problems, including the overly emphasizing on development and construction but neglecting operation and promotion. Compared with the UGC online platform, the knowledge service products developed by traditional academic publishing agencies have a poorer user experience and slower updates.

In order to accurately understand and assess the pilot projects, we carried out surveys and case collection of the pilot units and published the book "The Transformation of Knowledge-based Services in the Publishing Industry". The book collects and introduces 88 knowledge-based service platforms or products of these pilot units.

In addition, during the COVID-19 pandemic, WeChat official account, a Chinese knowledge-based service platform, launched the "knowledge safeguard the war against pandemic" initiative [12]; since then there have been professional and influential knowledge service agencies and platforms, such as publishing houses, journals and libraries, Internet companies, etc. actively responded, leveraging their respective advantages and characteristics to provide diverse, professional and accurate knowledge content for different industries and different groups of people.

At the same time, the Internet and new media have also responded positively. For example, Dedao App has cooperated with many Chinese publishing houses to establish a designated reading bloc to provide the public with knowledge on pandemic prevention. On the 26th of January, the QQ reading app of the Reading Group launched the "Science-based Knowledge for Challenging Times" reading area and published more than 20 books authored by authoritative centers, experts and scholars specialized in disease control and prevention, to help readers understand more about the pandemic.

\section{Knowledge-Based Service of Internet Companies and New Media}

Paying for knowledge online is an important knowledge-based service model that the Chinese Internet and new media companies have been exploring in recent years. The rise of paying for knowledge online can be attributed to the Internet technologies that promote content transmission, the convenience of online payment and people's demand for knowledge. From its emergence to prevalence, "paying for knowledge online" is on the course of rapid development in just 2 or 3 years. At present, the paid knowledge industry generally believes that such a model is a new format of the intersection of media, publishing and education. The products launched by Chinese Internet and new media companies usually process knowledge in a certain field into graphics, audio, video and other forms and deliver through online reading, online learning and online payment. 
Paid knowledge, an emerging content monetization model, became public in 2015 and quickly swept through the Chinese market in the next few years. Ximalaya, Dedao App, LRTS, Qingting FM, etc. have become a group of paid knowledge platforms that are thriving in the Chinese market. They seize big $\mathrm{V}$ resources and lay out high-quality contents, attracting a large number of users to pay for subscriptions. The data shows that the scale of China's paid knowledge market in 2018 was RMB 16.58 billion, a year-on-year increase of $91 \%$, and the user was 270 million people, a year-on-year increase of $42.1 \%$ [13]. In the next few years, the scale of the market and the number of users will continue to grow. This is mainly due to the slow growth of traditional publishing, education, media and other industries, and the migration of people's knowledge needs to online; at the same time, since the foundation of the We-Media has been relatively solidified, more vertical professionals will join knowledge-based service industry where there are faster cash flow and more room for growth.

However, the development of paid knowledge comes with doubts. Data show that the average repurchase rate of paid internet content in China was only $30 \%$ in 2018. Among consumers who have used the paid content, $28 \%$ were satisfied with the experience, $49.7 \%$ rated it average, and $12.3 \%$ not satisfied [14]. The market's doubts about paid knowledge payment are mainly manifested in the following aspects: First, is the model a "pseudo-proposition"? More users have found that many paid knowledge products do not help them to achieve a significant improvement in their professional ability or a significant increase in financial income; many wonder whether this fragmented knowledge is just a way to ease anxiety. Second, the product quality is uneven, and there is no unified measurement and supervision standard on the market. Currently, the paid contents on the market generally ask for payment before consumption. Even with sample reading or audio files, it is often difficult to judge the quality of the rest of content. The third is that the marketing model is not standardized, and some even arouse negative perception, such as flooding the website through circle of friends, "pyramid-scheme" business model, intentinduced marketing and so on.

Although the paid knowledge contains the word "paid", the degree of conversion is not high. This study estimates that the average paid conversion rate of the first four platforms in 2018 was only $6.31 \%$, which is significantly different from the level of entertainment products such as online games, online videos, live streaming, and animation. According to the statistics from the ITjuzi Venture Capital Event Database, this study found that there were 21 financing events in the primary market of China's paid knowledge industry in 2018; when compared with only 9 in 2017, the capital attention rate increased rapidly with the investment amount increased to RMB 868 million in 2018, an increase of $113 \%$ year-on-year while maintaining a relatively high growth momentum. In terms of investment rounds, the investment events in this industry in 2018 were mainly concentrated in the early stage. The 21 investment events were all in round B and before. Among them, the amount of investment in the round A and before reached 95\%. The paid knowledge market is still in the early stage of development.

Due to its values in cultural communication and educational enhancement, paid knowledge online is commended and supported by policies and mainstream media, 
which is a good external environment for development. As people's demands for quality contents continue to increase, more and more people will be willing to pay for contents of premium quality. After all, compared to free stuff, fee implies access to better content and a better experience.

\section{References}

1. Machlup F. The production and distribution of knowledge in the United Sates. Whitefish: Literary Licensing LLC; 2013.

2. Drucker P. The age of discontinuity. New Brunswick: Transaction Publishers; 1992.

3. The Consortium for Service Innovation [EB/OL]. www.thekcsacademy.net/kcs/kcs-resources/.8. 23 Aug 2019.

4. Chen Y. Call for knowledge-based services. Enterp Reform Manag. 1999;6:4.

5. Qi J. Archives should also promote "knowledge-based services". Secr Work. 1998;11:36.

6. Li J. Research on the characteristics and model of knowledge-based service. Intell Inf Work. 2004;2(8):16-8.

7. Liu G, Wang H. Organization and implementation of knowledge-based service based on Blog. Inf Theory Pract. 2008;5:702-5.

8. Qin X, Li C, Mai F. The contents, features and conceptual model of big data knowledge-based service. Inf Inf Work. 2013;2:18-22.

9. Tang X, Li X. Research on knowledge management service based on artificial intelligence. Libr Sci Res. 2017;13:26-31.

10. Chen X, Yun Z, Wan X. Media integrated precision knowledge service promotes the supply-side reform of academic journals. Chin J Sci Tech Period. 2017;28(9):805-9.

11. Jin Hua, Yifan Zhang. On building the relationship between digital publishing and paid knowledge ecology. Technol Publ. 2018;1:84-8.

12. Knowledge safeguard the battle against epidemic: let the publishing sector's knowledge-based service build a solid fortress for victory over the pandemic - a proposal of Knowledge Resource Service Center to all publishing units.

13. Bida. 2019 Paying for Knowledge Online Q1 Report: Industry scale maintains high growth rate [EB/OL]. http://www.cnsoftnews.com/news/201906/78569.html. 2019-06-13[2020-06-23].

14. The paid knowledge industry moves towards rationality. China Intellectual Property Information Network [EB/OL]. http://www.iprchn.com/Index_NewsContent.aspx?NewsId=112713. 2018-12-13[2020-06-23].

Publisher's Note Springer Nature remains neutral with regard to jurisdictional claims in published maps and institutional affiliations. 